\title{
IPTU E A PEC 110/2019 (REFORMA TRIBUTÁRIA): TEORIA, PRÁTICA, INSENSATEZ E RETROCESSO
}

The urban property tax (IPTU) and the taxation bill 'PEC 110/2019': Theory, practice, nonsense, and throwbacks

\section{Claudia M. De Cesare}

Pesquisadora e Consultora. PhD pela Universidade de Salford, Inglaterra, com tese sobre análise de equidade no imposto sobre a propriedade imobiliária. No Setor Público, trabalhou por 25 anos em tributação imobiliária em Porto Alegre. Conselheira do International Property Tax Institute [IPTI]. Membro do Teaching Faculty do Lincoln Institute of Land Policy. Professora do Programa Nacional de Capacitação das Cidades e da UFRGS (Extensão em Educação Fiscal) (Porto Alegre, RS, Brasil). Diretora da CMDeCesare \& Associados.

\section{Cintia Estefania Fernandes}

Procuradora de Curitiba, PR, Brasil. Doutora em Gestão Urbana (PUCPR). Mestre em Direito do Estado, Direito Tributário (UFPR). Especialista em Políticas de Solo Urbano pelo Lincoln Institute of Land Policy (MA-EUA). Membro do Teaching Faculty do Lincoln Institute of Land Policy. Professora do Programa Nacional de Capacitação das Cidades (Ministério das Cidades - MDR), do Instituto Brasileiro de Estudos Tributários (IBET), da ABDCONST, do UNICURITIBA. Presidente da Comissão de Direito à Cidade (OABPR). Vice-presidente da Comissão Nacional CEDU (OAB).

\section{Gelson Santos Oliveira}

Auditor Fiscal da Secretaria Municipal da Fazenda (SEFAZ) de Salvador, BA, Brasil. Membro da Coordenação Técnica da Planta Genérica de Valores. Ex. Gerente de Auditoria Fiscal do Grupo Especializado de IPTU e Conselheiro do Conselho Municipal de Contribuintes. Bacharel em Direito Universidade Federal da Bahia (UFBA). Especialista em Direito Tributário - Fundação Faculdade de Direito (UFBA). Planejamento Urbano e Gestão de Cidades (UNIFACS). Professor em cursos e treinamentos em matéria de tributação Imobiliária (IPTU e avaliação de imóveis para fins tributários).

\section{Pedro Humberto B. Carvalho Junior}

Pesquisador do Instituto de Pesquisa Aplicada (IPEA) (Rio de Janeiro, RJ, Brasil). PhD em Política Tributária pela Universidade de Pretória, África do Sul, com tese sobre o desempenho do IPTU no Brasil. Autor de várias publicações sobre impostos ao patrimônio em periódicos nacionais e internacionais. Organizador e palestrante em seminários na área de tributação. 


\title{
Resumo
}

Este artigo analisa a proposta de substituir o Imposto Predial e Territorial Urbano (IPTU) no Brasil por um imposto sobre o valor da terra desconsiderando as construções, constante no relatório da PEC 110/2019, cuja autoria é do Senador Roberto Rocha. A viabilidade da sua instituição é examinada considerando aspectos legais, questões relativas a sua implementação e benefícios potenciais. Com base em análises empíricas retratando a realidade brasileira, é demonstrada a desvinculação do imposto sobre o valor da terra com a capacidade contributiva, pois a carga tributária seria transferida para os imóveis de baixo valor, pequenos, padrão construtivo inferior e antigos. Seriam observadas iniquidades de caráter avaliatório e ausência de isonomia entre proprietários de bens de valor idêntico. A proposta resultaria em forte regressividade principalmente no caso de municípios altamente urbanizados e verticalizados. Além de manter a base de cálculo do IPTU inalterada, é também recomendado que os municípios continuem exercendo a plena competência para fixar as alíquotas deste imposto, evitando retrocessos na autonomia municipal que prejudicariam o interesse local, a justiça social imobiliária e o pacto federativo.

Palavras-chave: IPTU. Imposto sobre o valor da terra. Regressividade. Capacidade contributiva. Justiça social imobiliária. Autonomia municipal.

\begin{abstract}
This paper analyses a proposal for replacing the urban property tax in Brazil by a land value tax, which is presented in a report on a taxation bill - PEC 110/2019 - prepared by Senator Roberto Rocha. The feasibility of moving towards a land-valued based system is examined in the paper, considering legal aspects, implementation issues, and potential benefits. Based on empirical analysis covering the Brazilian reality, the study demonstrates no relationship between the land value tax and ability-to-pay since the tax burden would be transferred to low-value, small, old and low-quality properties. Valuation inequities would also be observed, as well as inequality among owners of same-valued properties. Moreover, the proposal would result in strong tax regressivity, especially for highly urbanized and verticalized cities. In addition to keeping the property tax levied on capital value, it is recommended that municipalities keep their full rights to set up the property tax, avoiding throwbacks in the fiscal autonomy that would cause prejudices on local interest, socio-property fairness and federative treaty.
\end{abstract}

Keywords: Urban property tax (IPTU). Land value tax. Regressivity. Ability-to-pay. Socio-property fairness. Municipal autonomy.

\section{Sumário}

1. Introdução; 2. Imposto sobre o valor da terra: fundamentação teórica; 3. Distribuição da carga tributária; 4. Análise do desempenho dos tributos imobiliários recorrentes; 4.1 IPTU; 4.2 ITR; 5. conclusões e recomendações; 6. Notas; Referências

\section{INTRODUÇÃO}

O relatório elaborado pelo Senador Roberto Rocha por intermédio da Comissão de Constituição, Justiça e Cidadania sobre a Proposta de Emenda Constitucional (PEC) 110/2019, cujo objeto é a reformulação do Sistema Tributário Nacional (STN), tem sido objeto de discussão em diferentes fóruns e grupos que analisam os encaminhamentos relacionados à reforma tributária, integrados por administradores e gestores tributários, tributaristas, procuradores públicos, municipalistas, acadêmicos, pesquisadores e demais especialistas em tributação.

Não obstante as 141 emendas discutidas no relatório, o relator propõe alterações adicionais no projeto de reforma tributária inspiradas no "debate com vários setores da sociedade e estudiosos do tema" conforme explica o Senador. Entre estas alterações, é recomendado que a base de cálculo do Imposto sobre a Propriedade Predial e Territorial Urbana (IPTU) seja alterada para o valor da terra desconsiderado as construções (ver item xix, p. 28). ${ }^{1}$ É, também, proposto o estabelecimento, por intermédio de lei complementar, de alíquotas mínimas e máximas para o imposto proposto, limites para a concessão de isenções e benefícios fiscais, e critérios para a avaliação dos imóveis.

É preponderante que esta proposta seja analisada com cautela e rigor científico. Alterações na política tributária devem ser fundamentadas na avaliação dos seus impactos, 
visando evitar decisões insensatas e amadorismos que reduzam as receitas municipais, colocando em risco a continuidade da prestação de serviços públicos básicos, ou que resultem em regressidade na distribuição da carga tributária para a maior parte dos contribuintes. Em especial, é necessário contar com análises empíricas dedicadas a responder satisfatoriamente as seguintes questões centrais:

i. No contexto atual, um imposto exclusivamente sobre o valor da terra urbana, desconsiderando as construções, poderia apresentar potencial de arrecadação semelhante a um imposto cuja base de cálculo seja o valor integral do imóvel (terra e construções)?

ii. Em caso positivo, qual seria a alíquota que compensaria a perda de receita produzida pela exclusão das construções? Haveria o risco desta alíquota ser confiscatória para parte dos imóveis? Por outro lado, sem alteração das alíquotas, qual seria a perda na arrecadação?

iii. Em comparação ao IPTU, o imposto sobre o valor da terra irá melhorar ou piorar a relação entre ônus tributário e a capacidade contributiva das famílias? Haverá progressividade ou regressividade na redistribuição da carga tributária?

iv. Qual o risco que as unidades de alto padrão localizadas em condomínios verticais paguem um imposto simbólico? Quem ocupa torres verticais com grande número de pavimentos: as famílias ricas ou pobres?

v. Como seria o impacto do imposto sobre o valor da terra nos segmentos não residenciais (comércio, indústria e serviços)? Lojas e demais estabelecimentos mercantis horizontais sofreriam uma carga tributária desproporcional em comparação com unidades comerciais e de prestação de serviços localizados em condomínios verticais, como salas e consultórios?

vi. O imposto sobre o valor da terra incentivaria a demolição desnecessária de prédios e imóveis que apresentam condições satisfatórias de habitabilidade, visando incentivar que as cidades sejam mais compactas?

vii. Considerando o perfil fortemente heterogêneo dos municípios brasileiros, quanto o valor da terra representa em relação ao valor integral do estoque imobiliário nas diferentes cidades e tipos de imóveis?

viii. Considerando ainda que a maioria dos municípios nos quais o IPTU é uma receita relevante tem um perfil eminentemente urbano, qual o percentual de terrenos baldios nestas cidades? É algo relevante em relação aos imóveis edificados?

ix. Em cidades consolidadas, é mais viável estimar com precisão o valor dos imóveis construídos ou o seu valor desconsiderando as construções?

x. E quanto ao cadastro imobiliário, o imposto sobre o valor da terra permitiria a exclusão das construções para resultar em um sistema mais simplificado?

xi. Considerando a legislação vigente, existem mecanismos para combater a especulação imobiliária no Brasil? 
É de suma relevância mapear, de forma transparente, quais as classes de contribuintes beneficiados e prejudicados com a substituição do IPTU por um imposto ao valor da terra. Este artigo busca refletir, em caráter preliminar, sobre as questões supra relacionadas visando analisar a viabilidade de introduzir um imposto sobre o valor da terra no contexto brasileiro, considerando aspectos legais, questões relativas a sua implementação e benefícios potenciais. O artigo abrange a revisão da teoria relacionada ao imposto sobre o valor da terra (conhecido como Land Value Taxation); examina os resultados de análises empíricas sobre a sua aplicabilidade no Brasil, mais especificamente, na cidade de Porto Alegre; e discute o desempenho do IPTU e ITR. Por fim, são apresentadas as principais conclusões e recomendações da análise.

\section{IMPOSTO SOBRE O VALOR DA TERRA: FUNDAMENTAÇÃO TEÓRICA}

Economistas clássicos do Século XIX, incluindo David Ricardo, reconheceram que o imposto sobre o valor da terra que não causa distorções econômicas (NETZER, 1998). Com base fundamentalmente nos estudos de John Locke e Henry George, a teoria liberal fornece as principais premissas econômicas para sua fundamentação, que resultam do reconhecimento de que recursos naturais - terra, ar ou água - são bens públicos que pertencem a todos, justificando assim a arrecadação integral da renda que poderia ser extraída destes bens pelo Estado (PLASSMANN, 1997). Tideman (1991) enfatiza que é o fluxo, ao invés do estoque, dos recursos naturais, isto é, a renda extraída destes bens, que deve ser alocada igualmente para a comunidade.

No livro 'Progresso e Pobreza', publicado em 1879, Henry George defende a aplicação de um imposto único sobre o valor da terra para compensar a injustiça causada pela propriedade privada. $\mathrm{O}$ autor explica que a renda da terra pode ser entendida como uma fonte de enriquecimento sem causa, pois não é uma consequência de ações realizadas pelos seus proprietários. Inspirados pelas ideias de Henry George, nove economistas foram agraciados com o prêmio Nobel em economia. ${ }^{2}$

Do ponto de vista econômico, a tributação sobre o valor da terra desconsiderando as construções é enaltecida pelo fato de que este imposto não distorce decisões econômicas devido ao fato de que a oferta da terra é fixa (BRUECKNER, 1986). Em contraste, decisões sobre investimentos em construção ou equipamentos podem variar devido a maior ou menor incidência tributária. Como observam De Cesare et al. (2003), a terra apresenta as seguintes particularidades:

- é um recurso natural inesgotável que não deprecia com o tempo;

- devido a sua imobilidade, a demanda excessiva em certa localização não pode ser compensada pelo seu excesso em outra área;

- devido a sua visibilidade, é um bem que não pode ser omitido, embora a manutenção de um cadastro territorial atualizado seja um grande desafio em países com assentamentos informais e parcelamentos irregulares;

- é um insumo primordial para a satisfação de necessidades básicas de moradia e trabalho. 
Seu valor é determinado exclusivamente pela demanda local, embora seja influenciada por fatores externos, tais como: mudanças demográficas, crescimento econômico, e nível de investimento internacional. Para Henry George (1879), o valor da terra é fundamentalmente resultante de esforços coletivos, como gastos públicos em infraestrutura urbana e serviços básicos que "tendem a aumentar dramaticamente o valor dos imóveis beneficiados" (LICHFIELD; CONNELLAN, 1997). Além disso, o valor da terra está relacionado ao seu potencial construtivo.

A Tabela 1 classifica em três grupos os principais argumentos citados na literatura para justificar a instituição do imposto sobre o valor da terra.

Tabela 1: Argumentos em favor do imposto sobre o valor da terra

\begin{tabular}{|c|c|}
\hline Grupo 1: Éticos e filosớficos & $\begin{array}{l}\text { - Igualdade de direitos sobre recursos naturais } \\
\text { - Oportunidade para a captura de valor }\end{array}$ \\
\hline Grupo 2: Econômicos & $\begin{array}{l}\text { - Neutralidade em termos de eficiência econômica } \\
\text { - Inexistência de perdas de ef iciência (peso-morto) } \\
\text { - Estímulo ao desenvolvimento } \\
\text { - Redução dos custos da cidade (cidades compactas) } \\
\text { - Incidência econômica progressiva (imposto é pago pelo dono da terra)' } \\
\text { - Melhor alocação da terra }\end{array}$ \\
\hline Grupo 3: Administrativos & $\begin{array}{l}\text { - Simplificação do cadastro } \\
\text { - Impossibilidade de evasão tributária } \\
\text { - Menor custo para a avaliação dos imóveis }\end{array}$ \\
\hline
\end{tabular}

Fonte: DE CESARE et al. (2003).

Tideman (1999) entusiasticamente observa que, "impostos ao valor da terra são bons demais para serem verdade". Entretanto, Netzer (1998) alerta que o sucesso político do movimento Georgiano é extremamente limitado.

De fato, o imposto recorrente sobre bens imóveis é instituído na grande maioria dos aproximadamente 200 países existentes no mundo. ${ }^{7}$ Não obstante, apenas a Dinamarca, a Austrália e a Estônia estabeleceram um imposto puro ao valor da terra conforme Pinto (2020). No caso da Austrália, o imposto imobiliário instituído pelos Estados incide apenas sobre o valor da terra, entretanto, o imposto de competência municipal incide sobre o valor integral dos imóveis, incluindo terra e construções. ${ }^{8}$ Além dos três países citados, há a experiência de Mexicali, México. A Jamaica também introduziu o imposto sobre o valor da terra para motivar a reforma agrária. Possivelmente, devem existir outros países pequenos que optaram por essa alternativa. Na Nova Zelândia, a sua reduzida aceitabilidade resultou na inclusão do valor das construções em 1992.. Importante notar que tanto a Austrália como a Nova Zelândia são países de baixa densidade demográfica. Nos Estados Unidos, a grande maioria dos municípios emprega o valor integral do imóvel, incluindo as construções, exceto por alguns municípios do Estado da Pennsylvania que utilizam o graded-system no qual alíquotas mais elevadas são aplicadas ao valor da terra do que ao valor da construção.

Em suma, a grande maioria das localidades utiliza o valor integral do imóvel - terra e construções - como a base de cálculo do imposto sobre a propriedade imobiliária. Portanto, cabe a reflexão sobre quais os fatores que explicam o alto grau de rejeição do imposto 
sobre o valor da terra desconsiderando as construções no âmbito mundial. Obstáculos à sua implementação e falácias relacionadas aos argumentos apresentados na Tabela são discutidos na sequência:

\section{- Falta de comprovação empírica sobre os efeitos econômicos}

As evidências empíricas sobre os efeitos de excluir o valor das construções do imposto sobre a propriedade imobiliária na atividade de construção são limitadas. Estudos ${ }^{10}$ realizados entre 1980 e 2000 apresentam resultados contraditórios. Como enfatizado por Plassmann (1997), não há resultados consistentes que indiquem alterações nas decisões relacionadas à atividade da construção.

\section{- Efeitos controversos}

Andelson (2000) alertava há 20 anos atrás sobre o risco de super densificação urbana como efeito controverso desta política. Atualmente, as preocupações com densificação populacional excessiva estão em pauta devido ao risco de proliferação de doenças contagiosas, entre as quais merece destaque o Covid-19.

Com base no posicionamento de diferentes urbanistas americanos, Flint (2020) alerta para transformações urbanas prováveis no período post-pandemia abrangendo: aumento de espaços abertos nos imóveis; introdução de melhores sistemas de ventilação; viabilização de divisões flexíveis que permitam maior privacidade; redução no número de trabalhadores nos imóveis não residenciais devido ao trabalho remoto; e revalorização da vida nos subúrbios onde as famílias podem desfrutar de mais espaço. No Brasil, devido a intensificação do trabalho remoto, foi observada a transferência de muitas famílias dos seus apartamentos com espaço limitado nas cidades para casas de veraneio nos balneários ou na serra nos segmentos de renda média-alta e alta. Embora ainda seja cedo para assegurar quais as transformações urbanas terão caráter mais permanente, a tendência é que o enfrentamento traumático do Covid-19 motive a redução da densificação das áreas urbanas, desafiando a máxima de que as cidades devem ser compactas.

\section{- Desvinculação com a capacidade contributiva e risco de perda de receita}

McCluskey e Williams (1999) alertam que um imposto sobre o valor da terra limita significativamente a magnitude da base de cálculo, excluindo parte substancial da riqueza, principalmente em cidades urbanas consolidadas. Embora a perda de receita possa ser compensada pela elevação da alíquota, é imprescindível assegurar a existência de capacidade contributiva para arcar com o ônus tributário nas diferentes classes de imóveis devido à desvinculação entre o imposto e a riqueza. Devido à necessidade de renda monetária líquida para o pagamento do imposto, a inadimplência tende a aumentar quando a base de cálculo é desvinculada da renda do contribuinte (UN-Habitat, 2011), como ocorre com o imposto sobre o valor da terra.

\section{- Receio de confisco e pressões políticas}

Andelson (2000) alerta que impostos com alíquotas elevadas sobre a terra tendem a ser identificados como confiscatórios com base no argumento de que a terra foi adquirida de 
boa-fé e que a legislação garante os direitos de propriedade. Plassmann (1997) reconhece que o imposto pode criar injustiças e resultar em fortes pressões políticas.

\section{- Falácia nos argumentos de cunho administrativo}

Os argumentos de cunho administrativo em apoio ao imposto sobre o valor da terra são questionáveis. Por exemplo, a afirmação de que é impossível a ocorrência de evasão tributária não é verdadeira para cidades marcadas por assentamentos informais e parcelamentos irregulares. Em termos tributários, a maior dificuldade nestes casos consiste em identificar o contribuinte. Este desafio permanece inalterado independente da base de cálculo do tributo ser o valor integral do imóvel ou o valor da terra desconsiderando as construções.

A hipótese de simplificação do cadastro deve também ser descartada. O Poder Público necessita monitorar o estoque imobiliário e seu crescimento para fins de planejamento territorial, instituição de instrumentos de política urbana, e fiscalização das declarações do imposto sobre as transferências de imóveis. Como o Brasil possui longa tradição em tributação imobiliária, as edificações já integram os cadastros utilizados para o lançamento do IPTU. A sua exclusão das bases cadastrais seria, sem dúvida, um retrocesso.

A redução no custo das avaliações seria parcial, pois parte do esforço permanece inalterada. Por exemplo, os observatórios do mercado imobiliário ${ }^{11}$ necessitam ser mantidos para viabilizar a aplicação do método residual na avaliação dos terrenos; servir de base em avaliações desenvolvidas para fins de ITBI, desapropriações, e concessões de uso; e, embasar decisões de políticas urbanas. Cabe ainda notar que a avaliação de terrenos em cidades urbanas consolidadas é mais difícil do que a avaliação de bens cuja oferta é abundante no mercado de imóveis, tais como: casas, apartamentos, salas comerciais, lojas, e espaços de estacionamento (ver item a seguir).

\section{- Iniquidades de caráter avaliatório}

Observa-se forte consenso quanto a dificuldade de avaliar com acurácia o valor da terra excluindo as edificações (LICHFIELD; CONNELLAN, 1997; MCCLUSKEY; FRANZSEN, 1999). Conforme Arnott (2000), "não há formas consistentes de decompor o valor de um imóvel em terra e benfeitorias". O argumento é especialmente verdadeiro para cidades urbanas consolidadas onde inexistem terrenos baldios em áreas centrais, polos comerciais e outras áreas fortemente densificadas. Segundo Mills (1998), regras arbitrárias tendem a ser utilizadas, resultando em iniquidades de caráter avaliatório que prejudicam inclusive a eficiência econômica do imposto ao valor da terra. Devido a erros de grande magnitude nas avaliações, imóveis seriam tributados parcialmente e outros super tributados.

\section{- Falta de transparência, arbitrariedade e prejuízo ao direito de contestação}

Quanto aos imóveis edificados, os contribuintes conhecem ou tem condições de conhecer o preço dos seus imóveis. No imposto sobre o valor da terra, o exercício dos direitos à contestação por parte dos contribuintes de imóveis edificados fica prejudicado nas vias administrativas ou judiciais, devido à ausência de informação sobre preços da terra em imóveis construídos, principalmente no caso de imóveis em condomínios e bens localizados em 
DE CESARE, Claudia M.; FERNANDES, Cintia Estefania; OLIVEIRA, Gelson Santos; CARVALHO JUNIOR, Pedro Humberto B. - IPTU e a PEC 110/2019 (Reforma Tributária): teoria, prática, insensatez e retrocesso -

áreas consolidadas.

\section{- Percepção de regressividade}

O imposto sobre o valor da terra tende a ser percebido como injusto pelos contribuintes. Como observa Reece (1992), existe iniquidade entre quem possui bens de valor semelhante, bem como tende a beneficiar contribuintes que possuem maior capacidade contributiva. A seguir seguem alguns exemplos ilustrativos de situações relacionadas à percepção de injustiça.

- Cabe notar que a depreciação das construções é ignorada no cálculo do imposto sobre o valor da terra. Portanto, considerando as demais variáveis constantes, o proprietário de um apartamento novo pagaria imposto idêntico ao dono de um apartamento antigo. No entanto, dados de mercado indicam que, por exemplo, o valor de mercado de apartamentos com 40 ou 50 anos de idade pode representar menos da metade de um imóvel similar novo em mesma localização.

- $\quad$ A distinção no imposto lançado para dois prédios situados na mesma face de quarteirão é resultante das diferenças na área dos seus respectivos terrenos. Se um terreno onde está construído um prédio de 15 pavimentos com quatro apartamentos por pavimento for apenas 3 vezes maior do que o terreno de um edifício de dois pavimentos, sem elevador ou espaço de estacionamento, com quatro apartamentos por andar, o imposto a ser dividido por 60 apartamentos novos será apenas 3 vezes o montante a ser dividido entre 8 apartamentos antigos em prédio sem elevador ou espaços de estacionamento. Desta forma, imóveis de baixo valor podem pagar imposto significativamente maior do que imóveis novos de padrão superior.

As situações citadas ilustram diretamente a perda de conexão entre o imposto e a capacidade contributiva. Por razões que fogem ao escopo deste artigo, ${ }^{12}$ as cidades brasileiras consolidadas apresentam um perfil de ocupação altamente heterogêneo. A Figura 1 ilustra casos de condomínios verticais situados na mesma rua, ou face de quarteirão na cidade de Porto Alegre. Devido a heterogeneidade no perfil de ocupação do solo urbano na mesma zona, a aplicação de um imposto sobre o valor da terra desconsiderando as construções resulta em forte regressividade principalmente para unidades em condomínios verticais, onerando apartamentos pequenos, antigos, sem elevador e sem espaço de estacionamento.

Para haver equidade na tributação sobre a terra, a densificação urbana teria de ser uniforme. Portanto, os condomínios verticais antigos deveriam ser substituídos por novos empreendimentos. Considerando a carência habitacional e a escassez de recursos enfrentada no país, é improvável, além de insensato, pensar que parte substancial do estoque imobiliário de condomínios verticais que apresenta condições satisfatórias de ocupação será renovada para aumentar de forma homogênea o grau de aproveitamento dos seus lotes por intermédio de maior verticalização. Ainda assim, haveria iniquidade entre imóveis novos e antigos. Cabe ainda notar que nem todas as zonas apresentam condições de absorver tamanha verticalização. 
Figura 1: Prédios próximos de características heterogêneas no Bairro Menino Deus em Porto Alegre
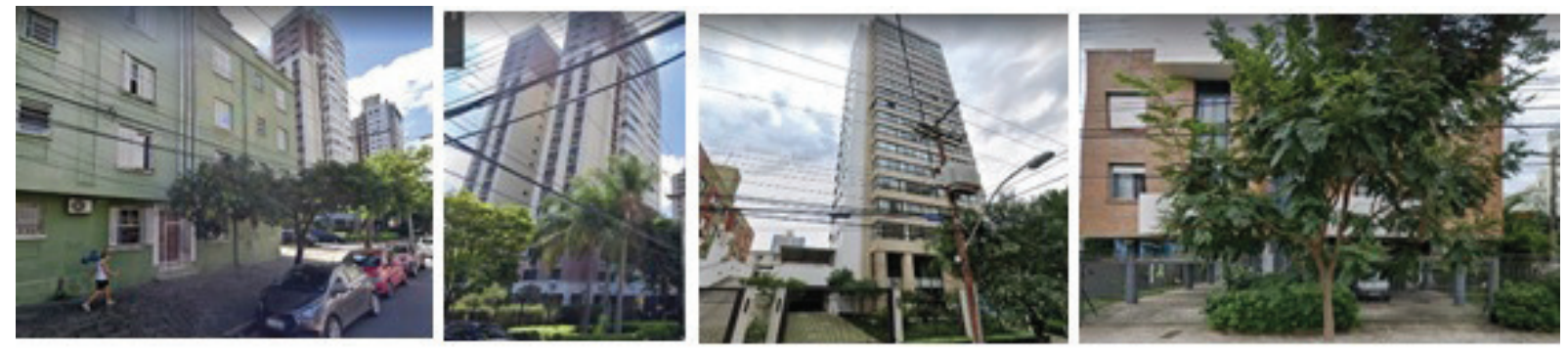

\section{DISTRIBUIÇÃO DA CARGA TRIBUTÁRIA}

Além de avaliar o impacto do imposto sobre o valor da terra na atividade de construção, a viabilidade da sua instituição depende da redistribuição da carga tributária nos diferentes segmentos de imóveis. Esta análise é particularmente relevante no caso de municípios altamente densificados no qual grande parte da população mora ou trabalha em prédios em condomínios verticais.

O único estudo encontrado na revisão bibliográfica a respeito da distribuição da carga tributária de um imposto sobre o valor da terra retratando a realidade brasileira foi desenvolvido por De Cesare et al. (2003). Este estudo analisa o impacto da mudança da base de cálculo do IPTU para o valor da terra desconsiderando as construções nos imóveis residenciais na cidade de Porto Alegre. Naquela época, os terrenos baldios representavam menos de $5 \%$ dos imóveis cadastrados.

Uma das premissas para realizar a análise foi assumir que a transição deveria ser neutra, isto é, não haveria nem perda nem incremento de receita no lançamento global do imposto. O estudo contemplou duas situações, quais sejam: i. receita a ser aferida pelo imposto sobre o valor da terra igual ao lançamento do IPTU vigente; ${ }^{13}$ ii. receita a ser aferida igual ao montante que seria lançado se os imóveis fossem avaliados a $100 \%$ do valor de mercado. A última situação descrita foi chamada no trabalho de 'hipótese de perfeita administração tributária'. Os resultados desta análise empírica são discutidos a seguir:

- Em termos globais, as residências unifamiliares - casas - teriam a carga tributária aumentada em $39 \%$, enquanto os apartamentos teriam uma redução de $38 \%$ em comparação com o IPTU vigente. Sob a hipótese de perfeita administração tributária, a carga tributária das casas aumentaria $78 \%$ ao invés de $39 \%$; e os apartamentos teriam uma redução global de imposto de $49 \%$, ao invés de $38 \%$.

- Em média, o IPTU vigente por apartamento representava $38 \%$ do imposto lançado por casa. Considerando o imposto sobre o valor da terra, a diferença iria aumentar, de forma que o imposto médio por apartamento representaria apenas $17 \%$ do imposto médio a ser pago por uma residência unifamiliar.

- Em comparação com o sistema vigente, caracterizado por subavaliações, foi estimado o seguinte impacto global por classes de imóveis:

- A carga tributária dos imóveis de menor valor (25\% dos casos) aumentaria $76 \%$; o aumento do imposto seria de $36 \%$ para imóveis de valor médio ( $50 \%$ dos casos); e, a carga 
tributária reduziria $16 \%$ para os imóveis de alto valor (25\% dos casos).

- $\quad$ Em relação as casas, haveria crescimento generalizado do imposto. Entretanto, a classe formada por imóveis de valor mais baixo seria a mais prejudicada (aumento de $260 \%$ ). Em contraste, haveria uma redução de $55 \%$ no imposto para a classe formada por apartamentos de alto valor. O imposto aumentaria $64 \%$ para os apartamentos de baixo valor. Quanto maior o número de classes nas quais os imóveis são agrupados, mais evidentes são os efeitos regressivos do imposto sobre o valor da terra.

- Mantendo coerência com os resultados anteriores, imóveis com maior área construída seriam beneficiados e imóveis pequenos seriam prejudicados: Por exemplo, o imposto aumentaria mais de $200 \%$ para a classe imóveis (casas e apartamentos) com área construída inferior a $40 \mathrm{~m}^{2}$, enquanto aqueles imóveis com área superior a $290 \mathrm{~m}^{2}$ teriam redução no imposto. No caso das casas, o impacto seria dramático para imóveis com área inferior a 90 $\mathrm{m}^{2}$, cujo aumento ultrapassaria $350 \%$.

Em relação ao padrão construtivo, reduções tributárias significativas seriam observadas em imóveis classificados como luxo (-75\%) e fino (-35\%). A perda desta arrecadação seria compensada por aumentos exorbitantes em construções de padrão precário, de alvenaria mista e de madeira, cujos acréscimos seriam respectivamente de $417 \%$, 375\% e 628\%.

- Na hipótese de perfeita administração tributária, isto é, se as avaliações fossem idênticas ao valor de mercado dos imóveis, os seguintes efeitos globais por classes de imóveis seriam esperados:

- O aumento do imposto seria semelhante - aproximadamente 70\% - para as casas de médio ( $50 \%$ dos casos) e alto valor ( $25 \%$ dos casos). Entretanto, o aumento seria de $160 \%$ para as casas de baixo valor. As três classes de apartamentos teriam redução do imposto, que seria mais acentuada para os apartamentos de alto valor.

- $\quad$ De forma semelhante ao sistema vigente, os prejuízos seriam maiores para as casas pequenas de baixo padrão construtivo, e maiores benefícios seriam desfrutados por apartamentos grandes, de alto padrão construtivo (fino ou luxo).

- Quanto ao impacto em nível individual, isto, é por imóvel:

- Na mediana, o imposto sobre o valor da terra resultaria no aumento de $62 \%$ para as casas, enquanto os apartamentos pagariam $66 \%$ do imposto atual (redução de $34 \%$ ). A variabilidade, medida pelo coeficiente de dispersão da mediana (COD), seria elevada (próxima a $200 \%$ ) para ambos os grupos, indicando forte heterogeneidade no impacto da transição.

Na hipótese de perfeita administração tributária, o aumento mediano seria ainda maior para as casas (aproximadamente $88 \%$ ) e os apartamentos pagariam apenas $33 \%$ da carga atual (redução de 67\%). O impacto seria mais uniforme em ambos os grupos, reduzindo a variabilidade para $45 \%$ e $126 \%$ respectivamente no caso das casas e apartamentos.

- $\quad$ Em nível individual, é confirmada a tendência de transferência da carga tributária para os imóveis de baixo valor, pequenos e de baixo padrão construtivo.

- Como discutido anteriormente, a avaliação de terrenos baldios (sem construção) em cidades consolidadas é problemática. Embora De Cesare et al. (2003) afirmam que apesar 
de ser factível desenvolver modelos hedônicos para avaliar os terrenos utilizando a estratégia de incluir casas anunciadas como terrenos na amostra de dados, erros e distorções de grande magnitude foram identificados nas estimativas de valor. Por intermédio da validação dos resultados, que foi realizada empregando uma amostra de dados não utilizados para desenvolvimento dos modelos, a dispersão da mediana entre o valor estimado dividido pelo preço de venda foi superior a $30 \%$, medida pelo coeficiente de dispersão, indicando a presença de iniquidades avaliatórias. O grau de acurácia das estimativas é significativamente maior nas avaliações de bens cuja oferta é abundante no mercado de imóveis, tais como: casas, apartamentos, salas comerciais, lojas, e espaços de estacionamento.

Os dados disponibilizados pelo Lincoln Institute of Land Policy (Tabela V-3) ${ }^{14}$ e por Carvalho Junior (2017) indicam que os terrenos baldios representam pequeno percentual dos imóveis cadastrados em cidades consolidadas, entre 3\% e 12\% em Aracajú, Belo Horizonte, Brasília, Curitiba, Florianópolis, Fortaleza, Porto Alegre, Recife, Rio De Janeiro, Salvador e São Paulo. No caso de elevado nível de desatualização cadastral, esses indicadores devem estar superestimados, pois parte das áreas cadastradas como terrenos foram informalmente loteadas, construídas e ocupadas. Em municípios menores com baixa densidade populacional, o número de terrenos baldios tende a ser maior.

- Devido ao baixo nível de avaliação dos imóveis em Porto Alegre na época do estudo, foi mais adequado verificar a alíquota necessária para a instituição de um imposto sobre o valor da terra considerando a hipótese de perfeita administração tributária. Neste caso, seria necessária uma alíquota de 3\% (3,5 vezes superior a alíquota original) para compensar a exclusão do valor das construções.

\section{ANÁLISE DO DESEMPENHO DOS TRIBUTOS IMOBILIÁRIOS RECORRENTES}

\subsection{IPTU}

Os municípios nos termos do art. 156, inciso I e $\S 1^{\circ}$ da Constituição Federal de 1988 possuem competência tributária para instituir o IPTU, cuja incidência abrange a propriedade, domínio útil ou posse de bem imóvel localizado em zona urbana ou áreas urbanizáveis (art. 32, Código Tributário Nacional, CTN, Lei no 5.172, de 1966).

O IPTU é um tributo direto, cujo perfil é estritamente local. Visando fortalecer o interesse local e a justiça social imobiliária, os municípios brasileiros são entes federativos que gozam de autonomia fiscal há mais de 30 anos nos termos constitucionais. Desta forma, as alíquotas, isenções e outros benefícios fiscais do IPTU são estabelecidos por lei municipal. A magnitude das alíquotas é decorrente da negociação entre governo municipal e seus munícipes sobre a abrangência e qualidade dos serviços públicos prestados. As alíquotas servem, também, para a consecução de objetivos extrafiscais, juntamente com as isenções tributárias e incentivos fiscais.

Com base nas premissas constitucionais, sua estrutura visa inconfundivelmente proporcionar que as famílias mais ricas contribuam mais com o financiamento das despesas públicas realizadas no âmbito local. Isto é decorrente da sua base de cálculo, que é o valor de mercado dos imóveis, incluindo terra e construções, bem como da viabilidade de aplicar 
alíquotas progressivas em razão do valor do imóvel nos termos do art. 156, Inciso I, $\S 1^{\circ}$.

Por outro lado, o IPTU viabiliza a integração entre política públicas, fiscais e urbanas. Com o objetivo de promover o uso racional da terra, reduzir a sua ociosidade, e desestimular a especulação imobiliária, é viável tanto instituir alíquotas mais elevadas aos terrenos baldios quanto progressivas no tempo, visando ao cumprimento da função social e ambiental da propriedade nos termos do art. 182, $\S^{\circ}{ }^{\circ}$, Constituição Federal e do art. $7^{\circ}$, Seção III, Estatuto da Cidade (Lei no 10.257, de 2001). Na América Latina, é relativamente comum a aplicação de alíquotas mais elevadas ou sobretaxas aos terrenos baldios para reduzir a especulação imobiliária, incluindo países como Argentina, Brasil, Equador, México e Venezuela. ${ }^{15}$

A receita proveniente deste instrumento é uma fonte importante de recursos para financiamento dos serviços urbanos de forma sustentável. Quanto maior o grau de urbanização de uma cidade, maior tende a ser o seu potencial de arrecadação. Nesta crise econômica, sem precedentes, produzida pelo Covid-19, a arrecadação de impostos recorrentes sobre bens imóveis, tais como o IPTU, caracterizada por ser menos sensível a choques econômicos, é preponderante para garantir a manutenção de serviços públicos essenciais.

Excluindo as contribuições sociais sobre o salário dos servidores municipais, o IPTU contribui com mais de $30 \%$ da receita tributária própria dos municípios. ${ }^{16}$ Seu crescimento como fonte de receitas superou 50\% entre 2010 e 2019, quando passou a representar aproximadamente $0,65 \%$ do Produto Interno Bruto (PIB), cifra inclusive um pouco superior à arrecadação do IPVA. Este crescimento demonstra o esforço fiscal de um número significativo de municípios na contratação de levantamentos em massa para atualização do cadastro territorial; criação de observatórios do mercado imobiliário; aprimoramento das rotinas internas de atualização contínua do cadastro territorial; reavaliação dos imóveis; e, aperfeiçoamento dos sistemas de arrecadação e cobrança do imposto, inclusive apostando na conscientização dos contribuintes por intermédio de programas de educação fiscal.

Não obstante a melhoria observada na última década, análises empíricas relativamente recentes, realizadas aplicando métodos distintos, estimam que o potencial de arrecadação do IPTU pode atingir entre 0,90\% e 1,25\% do PIB no Brasil (ver ORAIR E ALBUQUERQUE, 2017; CARVALHO JR., 2017; DE CESARE et al., 2014; e NORREGARD, 2013). Os seguintes aspectos prejudicam o desempenho do IPTU no Brasil:

\section{- Interferência do Poder Legislativo na atualização da base de cálculo do imposto}

Embora seja inquestionável a competência tributária garantida aos municípios no contexto constitucional, a Súmula $n^{0} 160 / 1996^{17}$ do Superior Tribunal de Justiça (STJ) determina que atualizações da base de cálculo do IPTU em percentual superior ao índice oficial de correção monetária necessitam ser realizadas por lei municipal. De forma injustificável, o IPTU é o único tributo cuja mera apuração da base de cálculo necessita de sanção do Poder Legislativo.

Sem interferências legislativas, a base de cálculo de qualquer outro tributo pode ser atualizada, inclusive no que se refere aos impostos ao patrimônio, cuja base de cálculo é idêntica à do IPTU, tais como: o Imposto sobre a Propriedade de Veículos Automotores 
(IPVA), Imposto sobre a Transmissão Intervivos de Bens imóveis (ITBI), Imposto sobre a Transmissão Causa Mortis e Doação (ITCMD), e Imposto Territorial Rural (ITR).

Além de desrespeitar preceitos constitucionais e legais, a Súmula expõe os gestores públicos a pressões políticas de grande magnitude para a mera atualização da base de cálculo do IPTU. Em processos marcados por profundo desgaste político, os municípios frequentemente ficam impedidos de exercer suas competências tributárias. Por exemplo, Porto Alegre ficou por 28 anos sem conseguir aprovar projetos de lei que tratavam da reavaliação de imóveis.

A desatualização da base de cálculo do IPTU produz injustiça fiscal e contraria o interesse coletivo, ferindo inclusive os princípios da isonomia e da capacidade contributiva contidos na Carta Magna. Enquanto algumas zonas da cidade ou tipos de imóveis valorizam; outras zonas ou tipos de imóveis depreciam. A manutenção de avaliações desatualizadas faz com que uma parcela dos imóveis pague mais do que deveria, prejudicando tipicamente imóveis que desvalorizaram e áreas nas quais não houve investimentos públicos. Em contraste, esta política tende a beneficiar os imóveis que valorizaram no período.

\section{- $\quad$ Falta de regulamentação de prazos máximos entre avaliações para fins de IPTU}

Ciclos máximos entre a reavaliação de imóveis para fins tributários é exigido por lei não apenas em países desenvolvidos, mas também na África do Sul, Argentina, Chile, Colômbia, Costa Rica, Equador, Guatemala e Uruguai. Em geral, os prazos máximos estabelecidos variam entre 2 a 5 anos.

Além de ser imprescindível para a equidade avaliatória, a regulamentação de ciclos entre as avaliações para fins de IPTU contribui para minimizar as pressões sobre os gestores públicos municipais. A inexistência de dispositivo legal sobre o tema no Brasil resulta em largos períodos entre as avaliações genéricas. Conforme De Cesare (2018a), os ciclos avaliatórios do IPTU superavam dez anos em 2017 em Vitória, São Luiz, Rio Branco, Porto Velho, Teresina, Natal, Belém, Maceió, Porto Alegre e João Pessoa. Antes da última reavaliação, a maior parte dos municípios estava sem reavaliar os imóveis para fins de IPTU por longo período: Curitiba (10 anos), Aracaju e Salvador (16 anos), Rio de Janeiro (20 anos), Recife (24 anos), e Manaus (28 anos). Como comentado anteriormente, Porto Alegre também ficou 28 anos sem reavaliar os imóveis; e João Pessoa está há mais de 40 anos sem promover a atualização completa no valor estimado dos imóveis.

Contudo a regulamentação de prazos máximos entre as avaliações desenvolvidas para fins de IPTU pode ser inócua se não for revertida a necessidade idiossincrática e injustificada de aprovar a atualização do valor venal por lei (ver item anterior).

\subsection{ITR}

Quanto à terra rural, a competência tributária é da União. Entretanto, a Emenda constitucional no 42/03 autorizou o governo federal a transferir por intermédio de acordo, a fiscalização e cobrança do Imposto Territorial Rural (ITR) aos municípios que assim optarem (art. $153,4^{\circ}$, III, Constituição Federal). Não é possível, entretanto, alterar os dispositivos legais constantes na Lei Federal no 9.393, de 1996, tais como: as alíquotas, forma de lançamento 
DE CESARE, Claudia M.; FERNANDES, Cintia Estefania; OLIVEIRA, Gelson Santos; CARVALHO JUNIOR, Pedro Humberto B. - IPTU e a PEC 110/2019 (Reforma Tributária): teoria, prática, insensatez e retrocesso -

do imposto, ou os casos de isenção e não incidência. Segundo o Ministério da Fazenda (2017), aproximadamente 2.100 municípios possuem convênio para fiscalizar e cobrar o ITR.

A arrecadação do ITR representa apenas entre $0,01 \%$ e $0,02 \%$ do PIB. Sua participação na carga tributária é irrisória e vem sendo reduzida de 0,08\% (1999) a 0,06\% (2019), conforme dados do Ministério da Fazenda (2000) e Tesouro Nacional. ${ }^{18}$

A legislação vigente é obsoleta. De Cesare (2018a) explica que, sem qualquer indício comprovado de eficácia, o ITR foi estruturado com a finalidade essencialmente extrafiscal de promover o aproveitamento eficiente da terra rural (art. 153, Inciso I, $\S 4^{\circ}, \mathrm{CF}$ ). A base de cálculo é valor da terra nua (VTN) tributável, desconsiderando as benfeitorias, estabelecido por autoavaliação (art. 80 e art. 10, da Lei Federal no 9.393, de 1996). A apuração e o pagamento do ITR são efetuados pelo contribuinte, sujeitos a eventual homologação, por parte do Fisco, posterior ao recolhimento do imposto. Além da base de cálculo excluir construções, instalações e benfeitorias, culturas permanentes e temporárias, pastagens cultivadas e meIhoradas, e florestas plantadas, as áreas não tributáveis abrangem um amplo número de situações. ${ }^{19}$ Há ainda uma série de situações de isenção e casos de não incidência tributária, tais como: pequenas glebas rurais, exploradas individualmente.

As alíquotas crescem em função da área dos imóveis e do seu grau de subutilização (art. $\left.153, \S 4^{\circ}, \mathrm{CF}\right)$, atributos que são declarados pelo contribuinte. A menor alíquota $(0,03 \%)$ corresponde praticamente à isenção e concentra a maioria das declarações. Desta forma, o ITR se torna o "imposto de 10 reais" para muitos, que é o valor mínimo legal do lançamento. ${ }^{20} \mathrm{Em}$ contraste, a alíquota máxima, que corresponde a $20 \%$, seria confiscatória se fosse efetivamente aplicada. Entretanto, casos da sua aplicação são desconhecidos.

Além disto, é indiscutível a forte heterogeneidade no perfil das áreas rurais no país. Conforme dados do IBGE, a área média de áreas de agricultura familiar é entre 5,5 ha e 10 hectares nos estados do Distrito Federal, Alagoas, Pernambuco e Sergipe; e superior a 50 hectares nos estados do Mato Grosso, Tocantins, Pará e Acre. Similarmente, é acentuada a variabilidade no tamanho médio dos estabelecimentos classificados na categoria não familiar, cuja média varia de 75 hectares (Sergipe) até 1.600 hectares (Mato Grosso). Em nível municipal, estas variações tendem a serem maiores. Uma área considerada pequena em um município, pode ser caracterizada como um latifúndio em outro. Estas diferenças dificultam o estabelecimento de regramento único para o país.

Conforme alerta Carvalho Junior (2018), em estados com crescimento do setor do agronegócio e do comércio de terras rurais, a arrecadação do ITBI - que abrange imóveis urbanos e rurais - é superior à receita do IPTU em: 60\% dos municípios localizados nos estados de Rondônia, Tocantins, Maranhão, Alagoas, Paraná, Mato Grosso do Sul, Mato Grosso e Goiás; $77 \%$ dos municípios localizados no Estado do Mato Grosso; e em 85\% dos municípios do Estado do Tocantins. Isto demonstra que limitar a competência tributária municipal aos imóveis urbanos pode prejudicar a capacidade de geração de receita própria de municípios com características rurais.

Cabe ainda enfatizar que a gestão administrativa do ITR por parte da União é deficien- 
te. O descaso pode estar relacionado ao acesso a outras fontes de receita mais rentáveis e fáceis de administrar. Farias, Silva e Leite (2017) sugerem que o desempenho insatisfatório do ITR está relacionado à falta de fiscalização, decorrente da distância entre contribuintes e o fisco, resultando na subdeclararão das áreas tributáveis e na super declaração do grau de utilização da área, bem como na impunidade decorrente da ausência de fiscalização e descaso na cobrança das dívidas. ${ }^{21}$

A praticamente ausência de tributação sobre os imóveis rurais representa não apenas um desperdício da base tributável, mas também aumenta o risco de comportamento especulativo. Além disto, a segmentação do imposto recorrente sobre bens imóveis em dois níveis distintos de governo produz as seguintes disfuncionalidades: i. duplicidades de esforço fiscal; ii. desperdício de dinheiro público para manutenção de duas bases territoriais distintas (cadastro urbano e cadastro rural); iii. disputas judiciais e, ocasionalmente, situações no qual parte das propriedades fica no limbo, não sendo tributadas nem pelo ITR nem pelo IPTU; iv. perda do controle pleno municipal sobre o ordenamento territorial, que é de competência exclusiva dos municípios.

\section{CONCLUSÕES E RECOMENDAÇOES}

Devido ao fato do IPTU ser menos sujeito ao impacto de flutuações econômicas, é um imposto essencial para manutenção de serviços básicos das cidades. Não obstante o seu potencial de melhoria, sua importância como fonte de receita cresceu $50 \%$ nos últimos dez anos, resultante exclusivamente de esforço administrativo de diversos municípios. Como explicado anteriormente, o IPTU está inconfundivelmente estruturado para proporcionar que as famílias e indivíduos mais ricos contribuam mais com o financiamento das despesas públicas realizadas no âmbito local.

A luta dos municípios brasileiros para um IPTU vigoroso, em termos tributários, sociais e urbanísticos, foi conquistada paulatinamente. Por exemplo, as restrições impostas pela Súmula no 668 do STF que impediam a aplicação de alíquotas progressivas em razão do valor dos imóveis foram superadas pela Emenda Constitucional no 29, de 2000, que reconheceu constitucionalmente a viabilidade de vincular o IPTU ao princípio da capacidade contributiva, possibilitando a progressividade, a redistribuição de riquezas, a observância do princípio da solidariedade e da realização do Estado Social Democrático de Direito (Fernandes, 2005).

As alterações propostas no relatório do Senador Roberto Rocha abrangem a substituição do IPTU por um imposto sobre o valor da terra desconsiderando o valor das construções e restringem a competência tributária municipal. Na prática, a maioria dos sistemas no âmbito internacional inclui o valor das construções na tributação dos imóveis. Os seguintes aspectos podem justificar a resistência a desconsiderar o valor das construções na base de cálculo do imposto sobre bens imóveis:

i. análises empíricas sobre os seus efeitos na atividade de construção apresentam resultados contraditórios;

ii. insegurança se a perda de receita gerada pela exclusão do valor das construções pode 
DE CESARE, Claudia M.; FERNANDES, Cintia Estefania; OLIVEIRA, Gelson Santos; CARVALHO JUNIOR, Pedro Humberto B. - IPTU e a PEC 110/2019 (Reforma Tributária): teoria, prática, insensatez e retrocesso -

ser compensada pelo aumento na alíquota;

iii. receio de confisco;

iv. receio de efeitos controversos, como super densificação urbana, que é agravado pela experiência traumática do Covid-19;

v. desvinculação entre o imposto e a capacidade contributiva;

vi. não há vantagem substancial em termos cadastrais, pois o desafio de identificar o contribuinte em áreas irregulares e assentamentos permanece inalterado;

vii. improbabilidade de simplificações nos sistemas de informação sobre preços praticados;

viii. probabilidade de arbitrariedades, iniquidades de caráter avaliatório e falta de transparência.

Ao analisar empiricamente o impacto de excluir o valor das construções da base de cálculo do IPTU no município de Porto Alegre para os imóveis residenciais, De Cesare et al. (2003) indicam que, em comparação ao sistema vigente, o imposto sobre o valor da terra iria onerar desproporcionalmente as residências unifamiliares e os imóveis de baixo valor em geral, produzindo aumentos exorbitantes em imóveis de padrão construtivo precário, alvenaria mistas e madeira, cujos acréscimos tributários seriam de $417 \%$, 375\% e $628 \%$ respectivamente. Em contraste, o imposto sobre o valor da terra beneficiaria os apartamentos, em especial, imóveis grandes, de alto valor, e padrão construtivo fino ou luxo. Analogamente, seria esperado um aumento significativo na carga tributária de lojas e demais estabelecimentos mercantis horizontais compensado pela redução significativa do ônus tributário das unidades comerciais e de serviços nos condomínios verticais.

Como ilustrado por intermédio de exemplos hipotéticos, imóveis antigos sem elevador ou espaço de estacionamento localizados em condomínios verticais pagariam o mesmo imposto que imóveis novos e modernos, pois a depreciação e obsolescência seriam ignoradas.

Além disso, avaliar com acurácia o valor de terrenos baldios é problemático, devido ao limitado número de transações em cidades consolidadas. Principalmente em áreas centrais, polos comerciais e outras áreas plenamente densificadas, os lotes estão edificados. De fato, em cidades maiores, os terrenos baldios representam entre $3 \%$ e $12 \%$ dos imóveis cadastrados. Em decorrência, é provável que regras arbitrárias sejam utilizadas nas avaliações, prejudicando inclusive a eficiência econômica do imposto sobre o valor da terra.

No caso de uma cidade com as características de Porto Alegre, claramente, a alteração da base de cálculo para o valor da terra desconsiderando as construções seria um equívoco insuperável. Para incentivar a atividade de construção, o imposto seria regressivo para mais de 95\% dos imóveis cadastrados. Além de onerar os imóveis de menor valor, haveria falta de isonomia entre proprietários de bens de valor idêntico. Dificilmente esta seria uma alternativa plausível para municípios altamente urbanizados e verticalizados.

No caso de comportamentos especulativos localizados, os municípios contam com instrumentos de política urbana, tais como o parcelamento, edificação e utilização com- 
pulsórias dos imóveis seguidas da aplicação do IPTU progressivo no tempo nos termos do Estatuto das Cidades. Além disso, a legislação atual permite a aplicação de alíquotas mais elevadas para os terrenos baldios. ${ }^{22}$ Cabe a cada município realizar um diagnóstico para entender os seus desafios e implementar estratégias eficazes de política urbana e tributária.

Portanto, deve ser descartada a hipótese de transformar o IPTU em um imposto sobre o valor da terra desconsiderando as construções no Brasil. Sua eventual aplicabilidade deveria ser limitada a cidades horizontais que tenham a maior parte dos seus lotes baldios ou parte significativa do território ocupada por glebas urbanas. Mesmo assim, sua aplicação deveria ser temporária. De toda a forma, análises empíricas seriam necessárias antes de cogitar qualquer alteração legal.

No tocante às alíquotas, a proposta do relator da PEC 110/2019 de estabelecer por lei nacional limites mínimos e máximos é, sem dúvida, um retrocesso. Esta alternativa é utilizada em fases iniciais de processos de descentralização. Os municípios Brasileiros são entes federativos, cuja autonomia fiscal foi garantida há mais de 30 anos nos termos constitucionais.

Os municípios devem ter plena autonomia para fixar as alíquotas do IPTU devido: (i) ao fato de conhecerem as especificidades locais do mercado imobiliário; (ii) à relevância das alíquotas para a concretização da política urbana local e da tributação progressiva; (ii) à necessidade de equilíbrio entre a magnitude das alíquotas e o nível das avaliações, que varia fortemente entre municípios e é desconhecido pelo parlamento nacional; (iii) à necessidade de dimensionar as alíquotas de acordo com as exigências orçamentárias. Como discutido anteriormente, é preponderante garantir que a magnitude da carga tributária do IPTU seja decorrente da negociação entre os governos municipais e seus munícipes sobre a abrangência e qualidade dos serviços públicos prestados.

Visando assegurar o interesse local e a justiça social imobiliária, é imperativo que a fixação das alíquotas do IPTU permanece sob a plena responsabilidade das Câmaras de Vereadores, que são instrumentalizadas por audiências públicas locais. A heterogeneidade dos municípios brasileiros prejudicaria inclusive a fixação de limites para as alíquotas aplicáveis. Cabe ainda salientar que em países onde há grandes interferências a nível nacional ou estadual no imposto imobiliário local, as receitas tendem a ser baixas. É o caso de Áustria, Alemanha, Noruega, México e Portugal, países que arrecadaram menos que 0,5\% do PIB em 2018, enquanto a arrecadação média dos países da Organização para a Cooperação e Desenvolvimento Econômico (OCDE) foi de 1,1\% do PIB.

Na realidade, as competências pelo estabelecimento de alíquotas, isenções tributárias ou incentivos fiscais, inerentes à autonomia municipal, são essenciais para o cumprimento do Pacto Federativo, art. $1^{\circ}$, da CF. Trata-se de uma cláusula pétrea constitucional (art. 60, $\left.\S 4^{\circ}, \mathrm{CF}\right)$.

Como leciona Kelsen (1998), a Democracia se concretiza com a descentralização do poder, portanto, descentralizar é pressuposto constitucional inegociável em um Estado Social Democrático de Direito. 
DE CESARE, Claudia M.; FERNANDES, Cintia Estefania; OLIVEIRA, Gelson Santos; CARVALHO JUNIOR, Pedro Humberto B. - IPTU e a PEC 110/2019 (Reforma Tributária): teoria, prática, insensatez e retrocesso -

Embora o fortalecimento do IPTU nos últimos 10 anos seja indiscutível, é viável avançar. Com o objetivo de aumentar a equidade e eficiência deste importante instrumento, é necessário que a reforma tributária absorva apenas dois aspectos:

- Estabeleça o intervalo máximo de 4 anos entre as reavaliações realizadas para fins de IPTU23

- Autorize os municípios a atualizar o valor venal dos imóveis por decreto ou instrução normativa para fins de IPTU como ocorre com os demais tributos.

Além disso, com o objetivo de viabilizar o ordenamento territorial pleno e garantir a racionalidade administrativa, o mesmo nível de governo deveria ser responsável pela tributação da terra urbana e rural, como ocorre na quase totalidade dos países. Seria, portanto, extremamente oportuno que a reforma tributária transferisse na íntegra a competência tributária do ITR aos municípios. A realização de convênios entre o governo federal e o fisco municipal para o repasse da fiscalização do imposto é insuficiente, na medida em que a estrutura legal para a sua instituição permanece inalterada.

Cabe ainda lembrar que a base de cálculo do IPTU inclui o valor da terra. Portanto, os benefícios econômicos do imposto ao valor da terra estão presentes nesta forma de tributação, embora sejam distintos dos efeitos da parcela do imposto que incide sobre o valor das construções. Portanto, a exclusão do valor das construções da base de cálculo do IPTU, além de gerar regressividade, seria um equivocado retrocesso.

\section{NOTAS}

1. Disponível em: https://legis.senado.leg.br/sdleg-getter/documento?dm=8050102\&ts=1594007105613\&disposition=inline.

2. Paul Samuelson (1970); Milton Friedman Nobel (1976); Herbert Simon (1978); James Tobin (1981); Franco Modigliani (1985); James Buchanan (1986); Robert Solow (1987); William Vickrey (1996); Joseph Stiglitz (2001).

3. A neutralidade do imposto sobre o valor da terra é relacionada ao fato do imposto não alterar decisões relacionadas a intensidade de densificação ou momento de desenvolvimento das áreas. Em outras palavras, decisões consideradas ótimas antes da aplicação do imposto permanecem ótimas após a sua instituição.

4. Tendem a ser observadas perdas de eficiência (peso-morto) em impostos que incidem sobre bens de oferta elástica, pois o imposto aumenta o valor de mercado do bem, desincentivando o consumo.

5. Autores da escola neoclássica como Bentick (1979), Mills (1981) e Oates e Schwab (1997), argumentam que o imposto sobre a terra não estimula o investimento, porque o valor da terra no presente já é dado pelo seu "maior e melhor uso".

6.A teoria econômica demonstra que, quando um imposto é tributado em um bem de oferta constante, independente do seu preço, a carga tributária é paga pelo proprietário do bem, que é incapaz de transferir o imposto aos usuários por intermédio da redução da sua oferta.

7. Disponível em: https://www.globalfromasia.com/tax-free-countries/.

8. Disponível em: http://www1.worldbank.org/publicsector/decentralization/June2003Seminar/Australia. pdf.

9. Disponível em: https://en.wikipedia.org/wiki/Taxation_in_New_Zealand. 
DE CESARE, Claudia M.; FERNANDES, Cintia Estefania; OLIVEIRA, Gelson Santos; CARVALHO JUNIOR, Pedro Humberto B. - IPTU e a PEC 110/2019 (Reforma Tributária): teoria, prática, insensatez e retrocesso

10. Edwards 1984; Mathias e Zech 1982; Weir e Peters 1986; Lusht 1992; Tideman e Johnson 1995; Oates e Schwab 1996; e Plassmann 1997. Lusht (1992) e Plassmann (1997) conseguiram identificar um impacto positivo do imposto na atividade de construção.

11. Sistema de informação destinado à coleta e armazenamento contínuo de dados de mercado, incluindo preços de oferta e venda de imóveis, cujo propósito é monitorar o mercado imobiliário e fornecer os dados necessários para a aplicação de diferentes métodos de avaliação de imóveis.

12. O regramento urbanístico muda com frequência. Por exemplo, prédios de 4 pavimentos sem elevador construídos nos anos 80 compartilham o espaço urbano com prédios novos de 15 ou mais pavimentos nos quais os condôminos desfrutam de áreas de lazer e vários espaços de estacionamento.

13. Na época, os imóveis estavam subavaliados para fins de IPTU.

14. Disponível em: https://www.lincolninst.edu/research-data/data/property-tax-latin-america.

15. Disponível em: https://www.lincolninst.edu/research-data/data/property-tax-latin-america (ver Tabela III-6).

16. Disponível em: https://sisweb.tesouro.gov.br/apex/f?p=2501:9::.:9:P9_ID_PUBLICACAO:32076.

17.

18. Disponível em: https://sisweb.tesouro.gov.br/apex/f?p=2501:9::::9:P9_ID_PUBLICACAO:32076.

19. incluem: a) áreas de preservação permanente; b) reservas legais; c) reservas particulares do patrimônio natural (RPPN); d) áreas de interesse ecológico; e) servidões ambientais; f) florestas nativas, primárias ou secundárias em estágio médio ou avançado de regeneração; g) áreas alagadas para fins de constituição de reservatório de usinas hidrelétricas.

20. Disponível em: https://valor.globo.com/brasil/noticia/2020/06/22/receita-quer-aumentar-arrecadacao-do-itr.ghtml.

21. A arrecadação do ITR foi de $R \$ 1,303$ bilhão em 2015. Entretanto, com base em dados da Procuradoria Geral da Fazenda Nacional, os autores relevam que aproximadamente 20 mil contribuintes acumulavam uma dívida de ITR de $R \$ 20,80$ bilhões (em média, $R \$ 1$ milhão por contribuinte).

22. Além de progressivas em razão do valor do imóvel, as alíquotas podem ser diferenciadas em razão do uso e da localização (art. 156, §1º, Inciso II, da CF).

23. O PLS 277/2014 (Complementar) alterava o artigo 11 da Lei de Responsabilidade Fiscal para estabelecer a atualização da Planta Genérica de Valores em periodicidade não superior a 4 anos. No entanto, o PLS foi negado no Plenário do Senado Federal em 5/8/2015 por 1 voto (40 votos favoráveis e 16 desfavoráveis do total de 81 senadores), devido à necessidade quórum especial, aliada a falta de debates sobre o tema.

\section{REFERÊNCIAS}

ANDELSON, R. V. Land-Value Taxation Around the World. Third Edition. Oxford, United Kingdom: Blackwell Publishers, Inc., 2000.

ARNOTT, R. Neutral Property Taxation. Program on Housing and Urban Policy, Seminar Paper Series S00-004, Institute of Business and Economic Research (Iben), 2000.

BENTICK, B. L. The impact of taxation and valuation practices on the timing and efficiency of land use. Journal of Political Economy, Chicago, v. 87, n. 4, p. 859-68, Aug. 1979. 
DE CESARE, Claudia M.; FERNANDES, Cintia Estefania; OLIVEIRA, Gelson Santos; CARVALHO JUNIOR, Pedro Humberto B. - IPTU e a PEC 110/2019 (Reforma Tributária): teoria, prática, insensatez e retrocesso -

CARVAlHO JUNIOR, P. H. B. Property Tax Performance and Potential in Brazil. 2017. Doctor of philosophy (PhD) - University of Pretoria, 2017.

CARVALHO JUNIOR, P. H. B. O Imposto sobre Transmissão de Bens Imóveis (ITBI). In: FAGNANI, Eduardo (org.). A Reforma Tributária Necessária: Diagnóstico e Premissas. Brasília: ANFIP, FENAFISCO; São Paulo: Plataforma de Política Social, 2018. p. 436-456.

BRUECKNER, J. K. A Modern Analysis of the Effects of Site Value Taxation. National Tax Journal, [Washington], v. 39, n.1, p. 49-58, 1986.

DE CESARE, C. M. Improving the Performance of the Property Tax in Latin America. Policy Focus Report. Massachussetts, US: Lincoln Institute of Land Policy, 2012.

DE CESARE, C. M. Sistemas del Impuesto Predial en América Latina y el Caribe. Editado por Claudia M. De Cesare. Cambridge, US: Lincoln Institute of Land Policy, 2016, p. 1-12; 37-7.

DE CESARE, C. M. Condições Básicas para Garantir a Funcionalidade da Tributação Recorrente ao Patrimônio Imobiliário Urbano e Rural. In: FAGNANI, Eduardo (org.). A Reforma Tributária Necessária: Diagnóstico e Premissas. Brasília: ANFIP, FENAFISCO; São Paulo: Plataforma de Política Social: 2018a. p. 369-393.

DE CESARE, C. M. Ponderações sobre Avanços Preponderantes para o Fortalecimento da Tributação Imobiliária no Brasil. In: MARENCO, André (org.). A Política, as Políticas e os Controles como são Governadas as Cidades Brasileiras. Porto Alegre: Tomo Editorial, 2018b. p. 65-98.

DE CESARE, C. M.; FERNANDES, C. E.; CAVALCANTI, C. Baima (org.). Caderno técnico para a regulamentação e implementação do imposto predial e territorial urbano. Brasília: Ministério das Cidades: Programa Nacional de Capacitação das Cidades: Lincoln Institute of Land Policy: CAIXA, 2016. $111 \mathrm{p}$.

DE CESARE, C. M.; YOSHINORI, M.; WENDT, S. C.; SILVA FILHO, L. C. P. Analyzing the Feasibility of Moving to a Land Value-based Property Tax System: A Case Study from Brazil. Working Paper. Lincoln Institute of Land Policy, 2003.

DE Cesare, C. M.; DANTAS, R. A.; PORTUGAL, J. L.; RIBEIRO, J. L. D. La Diversidad del Reto: Factores Críticos del Desempeño del Impuesto a la Propiedad Inmobiliaria en Brasil. In: BONET, Jaime Alfredo; MIRANDA, Andrés Muñoz; MANNHEIM, Carlos R. Pineda (ed.). El Potencial Oculto: Factores Determinantes y Oportunidades del Impuesto A la Propiedad Inmobiliaria en América Latina. Washington, US: Banco Interamericano de Desarrollo, 2014. p. 29-54.

EDWARDS, M. E. Site Value Taxation in Australia. American Journal of Economics and Sociology, v. 43, p. 481-495, 1984.

FERNANDES, C.E. IPTU. Texto e Contexto. São Paulo: Quartier Latin, 2005. 448 p.

FLINT, A. Future of Density: Affordability, Equity, and the Impacts of an Insidious Virus. Lincoln Institute of Land Policy, 2020.

GEORGE, H. Progreso y Miseria. [S. I.]: Robert Schalkenbach Foundation, 1996. Cuarta impression. 1. ed. em 1879. 
DE CESARE, Claudia M.; FERNANDES, Cintia Estefania; OLIVEIRA, Gelson Santos; CARVALHO JUNIOR, Pedro Humberto B. - IPTU e a PEC 110/2019 (Reforma Tributária): teoria, prática, insensatez e retrocesso -

KELSEN, Hans. Teoria Geral do Direito e do Estado. Tradução de de Luís Carlos Borges. 3. ed. São Paulo: Martins Fontes, 1998.

LICHFIELD, N.; COLLEMAN, O. Land Value Taxation in Britain for the Benefit of the Community: History, Achievements and Prospects. Working Paper WP98NL1. Lincoln Institute of Land Policy, 1997.

LUSHT, K. M. The Site Value Tax and Residential Development. Melbourne, Australia: Smeal College of Business Administration - The Pennsylvania State University, 1992.

MATHIAS, E.; ZECH, C. An Empirical Test: The Economic Effects on Land Value Taxation. Growth and Change, [S. I.], v. 13, p. 2-5, 1982.

MCCLUSKEY, W.; FRAZSEN, R. C. D. Land-value Taxation in Australia, Jamaica, Kenya, New Zealand and South Africa. In: IRRV Fifth International Conference on Local Government Property Taxation. Cambridge, USA: 1999.

MCCLUSKEY, W; WILLIAMS, B. Introduction: A Comparative Evaluation. In: McCluskey, Willian (ed.) Property Tax: An International Comparative Review. Hants, England: Ashgate Publishing Ltd., 1999, p. $1-31$.

MINISTÉRIO DA FAZENDA. Carga tributária no Brasil 2000: Análise por tributos e bases de incidência. Estudos Tributários. Brasília, DF: Ministério da Fazenda, 2001.

MINISTÉRIO DA FAZENDA. ITR Convênio. Consulta entes conveniados. Receita Federal do Brasil, 2017.

MILLS, E. S. The Economic Consequences of a Land Tax. In: NETZER, Dick (ed.). Land Value Taxation: Can It and Will It Work Today? Puritan Press, USA: Lincoln Institute of Land Policy, 1998. p. 31-48.

NETZER, D. Land Value Taxation: Can It and Will It Work Today? Lincoln Institute of Land Policy, 1998. $284 \mathrm{pg}$.

OATES, W. E. Local Property Taxation: An Assessment. The Value of Land: 1999 Annual Review. USA: Lincoln Institute of Land Policy, 1999. p 4-11.

OATES, W. E.; SCHWAB, R. M. The Impact of urban land taxation: The Pittsburgh experience. National Tax Journal, v. 50-1, p. 1-21, 1997.

PINTO, V. C. É Preciso Substituir o IPTU por um Imposto sobre o Valor da Terra. Caos Urbano, 2020.

PLASSMANN, F. The Impact of Two-Rate Taxes on Construction in Pennsylvania. 1997. PhD (Dissertation) (unpublished manuscript) - Virginia Polytechnic Institute and State University, 1997.

TIDEMAN, T. N. Taxing Land is Better than Neutral: Land Taxes, Land Speculation, and the Timing of Development. In: WENZER, Kenneth C. (ed.). Land-Value Taxation: The Equitable and Efficient Source of Public Finance. London, England: Shepheard-Walwyn (Publishers) Ltd., 1999. p. 109-133.

TIDEMAN, T. N.; JOHNSON, C. A Statistical Analysis of Graded Property Taxes in Pennsylvania. Working Paper WP95NT2. Lincoln Institute of Land Policy, 1995. 
UN-Habitat. Landy and Property Tax: A Policy Guide. Nairobi: United Nations Human Settlements Program, 2011.

VICKREY, W. Propositions Relating to Site-Value Taxation. In: WENZER, Kenneth C. (ed.). Land-Value Taxation: The Equitable and Efficient Source of Public Finance. London, England: Shepheard-Walwyn (Publishers) Ltd, 1999. p. 37-45.

WEIR, M.; L. E. PETERS. Development, Equity, and the Graded Tax in the City of Pittsburgh. Property Tax Journal, v. 5, p. 71-84, 1986.

Recebido em: 14/08/2020

Aceito em: 20/08/2020 